\section{EMBRYRIDDLE Aeronautical University}

SCHOLARLY COMMONS
International Journal of Aviation, Aeronautics, and Aerospace

10-30-2019

\title{
Cleared to Land: Pilot Visual Detection of Small Unmanned Aircraft During Final Approach
}

\author{
Ryan J. Wallace \\ Embry-Riddle Aeronautical University, ryan.wallace@erau.edu \\ Samuel M. Vance \\ Oklahoma State University - Main Campus, matt.vance@okstate.edu \\ Jon M. Loffi \\ Oklahoma State University - Main Campus, jon.loffi@okstate.edu \\ Jamey Jacob \\ Oklahoma State University - Main Campus, jdjacob@okstate.edu \\ Jared C. Dunlap \\ Oklahoma State University - Main Campus, jared.dunlap@okstate.edu \\ See next page for additional authors
}

Follow this and additional works at: https://commons.erau.edu/ijaaa

Part of the Aviation Safety and Security Commons

\section{Scholarly Commons Citation}

Wallace, R. J., Vance, S. M., Loffi, J. M., Jacob, J., Dunlap, J. C., Mitchell, T. A., Thomas, R., \& Whyte, S. R. (2019). Cleared to Land: Pilot Visual Detection of Small Unmanned Aircraft During Final Approach. International Journal of Aviation, Aeronautics, and Aerospace, 6(5). https://doi.org/10.15394/ ijaaa.2019.1421

This Article is brought to you for free and open access by the Journals at Scholarly Commons. It has been accepted for inclusion in International Journal of Aviation, Aeronautics, and Aerospace by an authorized administrator of Scholarly Commons. For more information, please contact commons@erau.edu. 
Cleared to Land: Pilot Visual Detection of Small Unmanned Aircraft During Final Approach

\section{Authors}

Ryan J. Wallace, Samuel M. Vance, Jon M. Loffi, Jamey Jacob, Jared C. Dunlap, Taylor A. Mitchell, Robert Thomas, and Seabrook R. Whyte 
The number of pilot-reported encounters with unmanned aircraft has been on the rise, since 2014 when the Federal Aviation Administration (FAA) first starting recording UAS encounter data. In 2018, UAS sightings climbed to 2,308 nationwide, a $90.7 \%$ uptick from just three years earlier (see Figure 1). The Aviation Safety Reporting System (ASRS), a self-reporting medium for pilots and other aviation professionals, recorded a similar rise in UAS-reported incidents (ASRS, 2019). Prior to 2014, UAS incident reports were relatively rare, however, in recent years ASRS reports involving unmanned aircraft have climbed to more than 100 reports annually (ASRS, 2019).

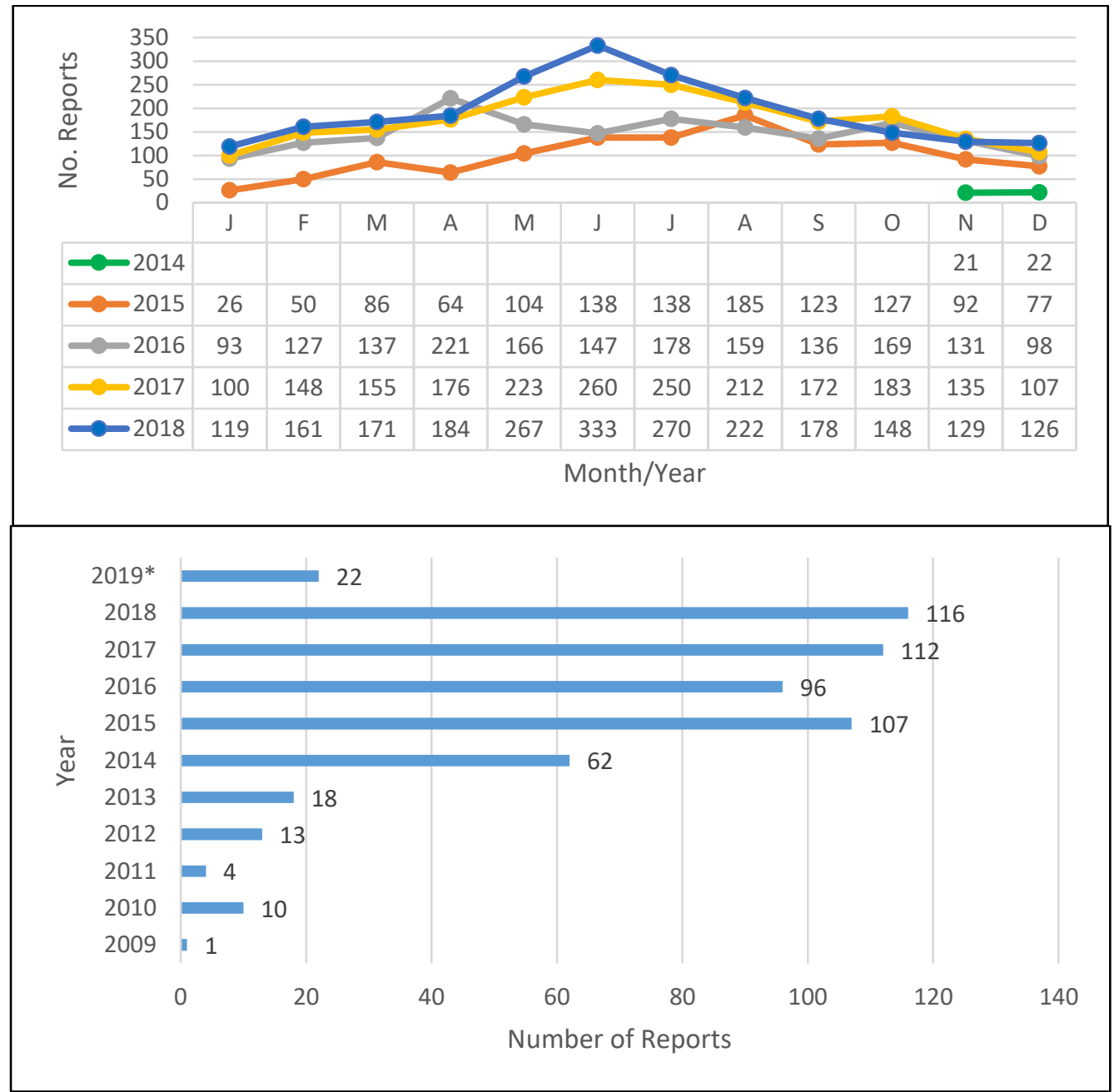

Figure 1. [Top] UAS Sighting Reports (U.S. only, November 2014 - December 2018). Derived from (FAA, 2019b). [Bottom] Aviation Safety Reporting System UAV Reports, March 2009-March 20, 2019. Derived from (ASRS, 2019). 


\section{UAS Encounters During Final Approach}

Perhaps more concerning is the number of reported UAS encounters during the final approach phase of flight. A report by Gettinger and Michel (2015) highlighted 17 reported incidents in which pilots encountered unmanned aircraft while on approach to Los Angeles International Airport (KLAX) between December 8, 2015 and August 15, 2015 (see Figure 2).

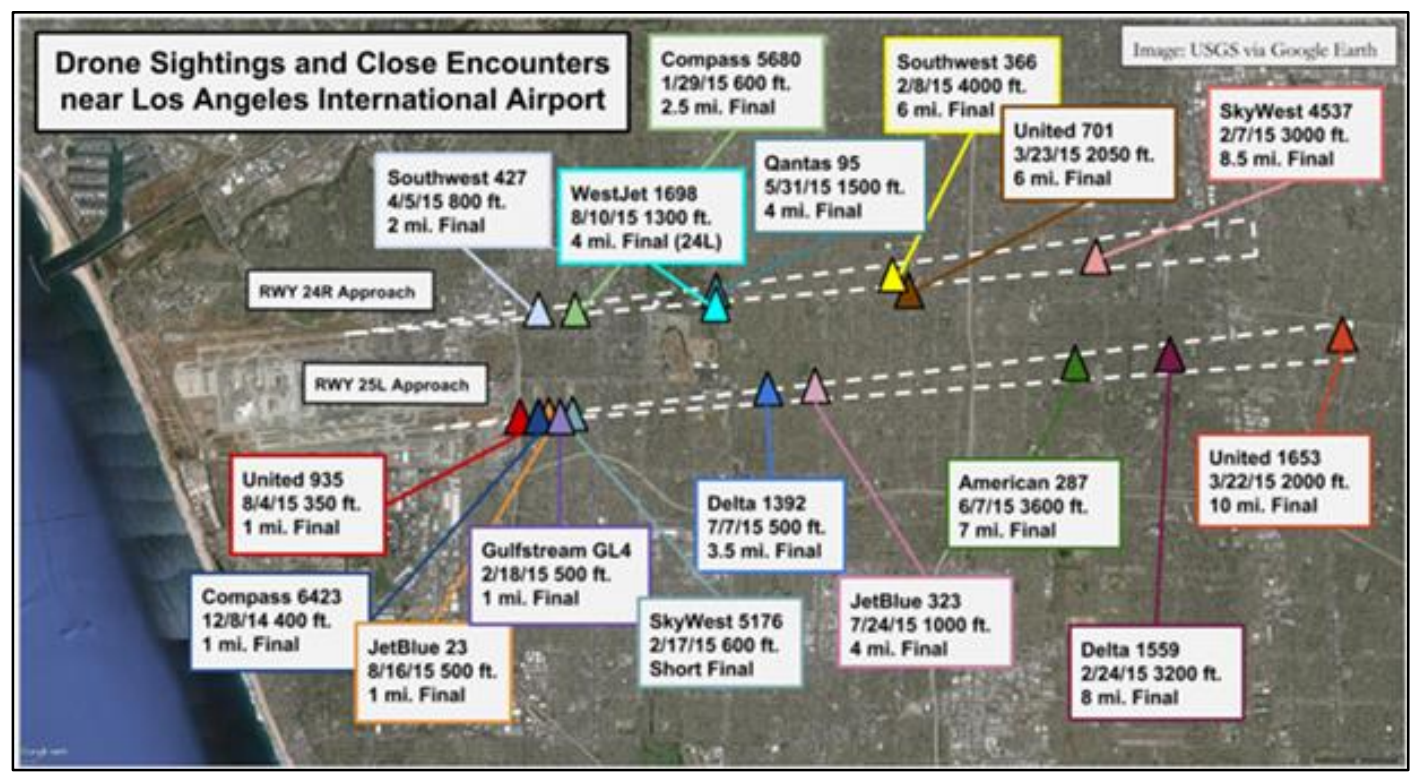

Figure 2. Drone Sightings and Close Encounters Around Los Angeles International Airport (LAX), December 8, 2015-August 15, 2015 (Gettinger \& Michel, 2015). Reprinted with permission.

In 2018, UAS sightings encountered during the final approach phase of flight ballooned to 526 a year, representing nearly $22.8 \%$ of all UAS sighting reports (see Figure 3). Moreover, unmanned aircraft are being encountered at distances and altitudes all along the approach corridor to airfields (see Figure 3). 


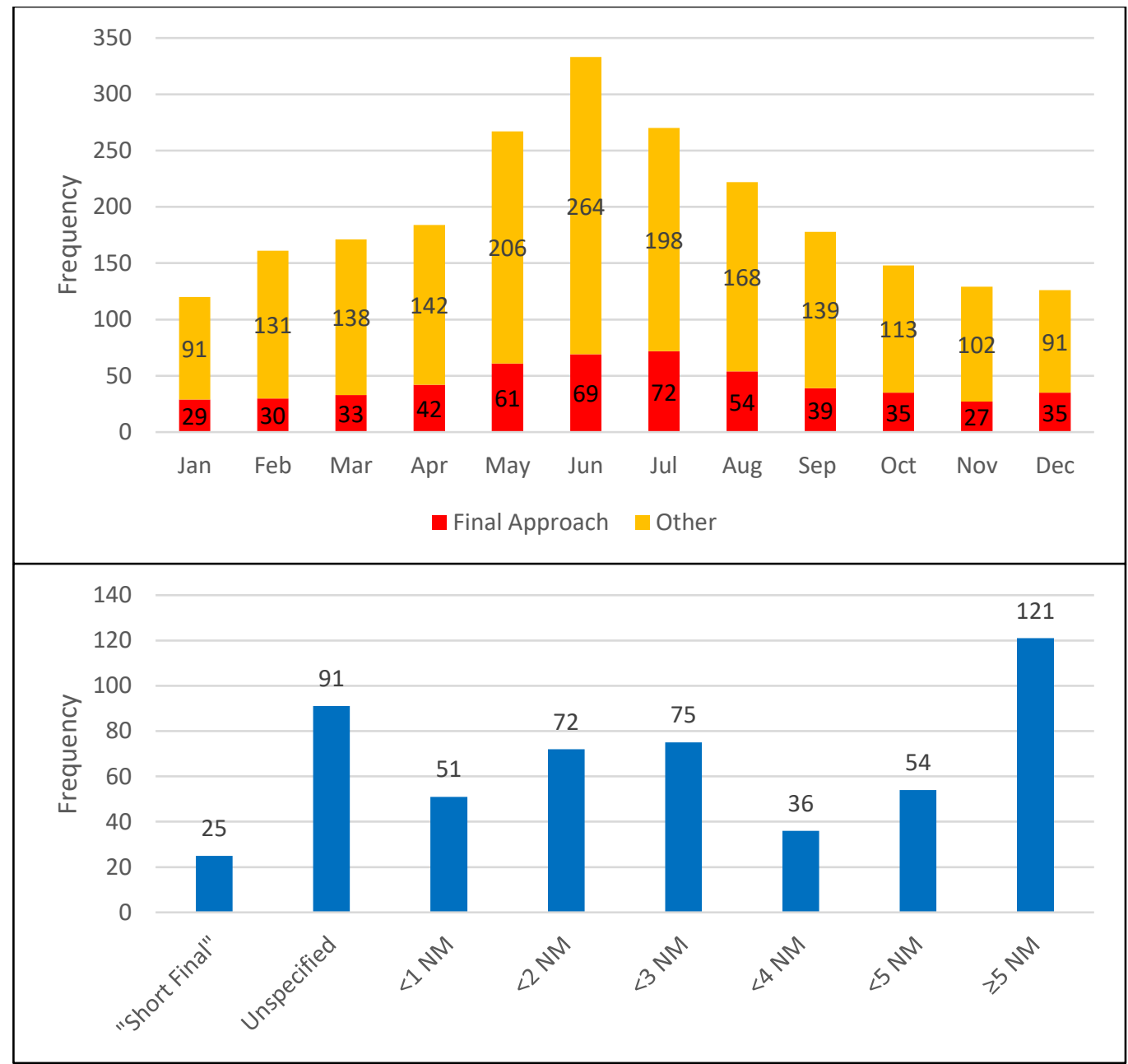

Figure 3. [Top] UAS Sighting Reports (U.S. only, CY 2018), with proportion of pilots reporting UAS encounters on final approach colored in red. [Bottom] UAS sightings reported while on final approach (U.S. only, CY 2018), based on distance from airfield. Derived from (FAA, 2019b).

\section{Flight Deck Dynamics During Final Approach Phase of Flight}

Final approach would typically be defined as the last segment of flight, generally extending $5 \mathrm{NM}$ (or more, platform dependent) from the airport to touchdown. In this phase of flight, a pilot's sole objective is to establish a stabilized, constant airspeed speed descent, constant rate of descent, minimizing aircraft configuration changes, and visual acquisition of the runway-endenvironment to facilitate a safe visual landing. In Visual Meteorological Conditions (VMC), these objectives are generally easier to meet than in Instrument Meteorological Conditions (IMC). Flight during IMC demands a 
precise balance of aircraft control and visual scrutiny of the outside world. During an IMC approach most airlines or professional, multi-crewed aircraft require the Pilot Flying to control the aircraft solely by reference to internal cockpit instruments, while the Pilot Monitoring would maintain responsibility for looking outside the cockpit for visual reference to the runway or other external hazards. As soon as this visual reference is gained, the Pilot Flying refocuses to the visual view to complete the landing.

In either the VMC or IMC environments, a pilot's attention would be focused straight ahead in the forward field of view. The ability to detect a conflicting sUAS would be hampered by any occlusion to vision, which could include a) the current inflight visibility, b) moisture, dirt, smoke or any other atmospheric occlusion, c) the sun positioning, especially at a low grazing angle to the horizon, or d) the aircraft cockpit window field of view (which may impede vision by the occluding strut structure).

Simply due to the small size, sUAS movement would most likely be necessary for visual detection. In IMC, if the approach is necessary to precision approach minima (typically no higher than 200' AGL), the amount of time available for a visual contact is measured in seconds and the sUAS would have to be similarly low to the ground, and moving. It is highly unlikely that at the bottom end of an IMC approach to minimums in the transition to VMC flight, that any visual sighting of a sUAS would occur, unless the sUAS were directly in front of the aircraft. In this case, an inflight collision would be imminent and likely unavoidable.

The FAA sightings reports show a disturbing and increasing volume of sightings both around and in the vicinity of the final approach corridor. This could be the result of more complete reporting, a true increase in unauthorized sUAS activity around airports, or both. To combat the inappropriate placement and use of sUAS, a NPRM was enacted early in 2019 for comment on, Safe and Secure Operations of Small Unmanned Aircraft Systems (FAA, 2019a); however, this rule effort did not specifically address the sUAS threat to landing aircraft or the final approach corridor. The collision threat to an aircraft on final approachparticularly, less-maneuverable, transport-category aircraft-is significant and could be exponentially more dangerous than light aircraft because of the higher mass and speed of the aircraft involved.

\section{Additional Challenges}

Aside from pilot-reported sightings, there is currently no reliable method for tracking UAS flights within the U.S. While the National Aeronautics and Space Administration (NASA) and the FAA are working to establish an unmanned traffic management solution to enable civil low-altitude UAS operations, such infrastructure is not yet in place (NASA, 2019). 
Complicating this issue is the current lack of standardization for remote identification and tracking. In June 2017, the FAA's UAS Identification and Tracking Aviation Rulemaking Committee (UAS ID ARC) released its report recommending the agency consider implementation of both direct broadcast and network publishing of UAS operations. Of the UAS ID ARC's 74 members, 8 did not concur with the report's findings, 20 concurred with exceptions, and 12 gave no response (UAS ID ARC, 2017). As of October 2019, the UAS ID ARC has not published further guidance.

While the FAA has made strides to secure controlled airspace from UAS incursions, their efforts have been met with mixed results.

\section{Problem}

The threat of a midair collision between a sUAS and manned aircraft is heightened during the final approach phase of flight, as aircraft transition from higher-altitude airspace into the low altitude arena now populated by small unmanned aircraft. Absent benchmarks for electronic detection and sense and avoid systems, pilots rely primarily on visual senses and proper visual scanning techniques to ensure a positive separation and collision avoidance from sUAS platforms during this segment of flight. Past studies have been inconclusive regarding the efficacy of visual methods for avoiding, reacting to, and maintaining separation from sUAS in the NAS.

\section{Purpose}

The purpose of this research was to evaluate the effectiveness of pilot visual detection of unmanned aircraft during an instrument approach to landing scenario. This research serves to better understand the human factors implications for pilots in detecting and avoiding potential collision conflicts with small unmanned aircraft systems in the approach and landing environment. The authors sought to examine pilot mean visual detection distances to a sUAS craft that would pose a potential collision risk during the visual portion of a simulated instrument approach. This research represents the third in a series of related field experiments regarding sUAS detection, visibility, and collision avoidance (Loffi, Wallace, Jacob, \& Dunlap, 2016; Wallace, Loffi, Vance, Jacob, Dunlap, \& Mitchell, 2018). The authors sought to codify operational strategies for pilots to improve visibility, detection, and collision avoidance of small unmanned aircraft operating in the National Airspace System.

\section{Research Questions}

The authors sought to answer the following research questions: 
- What is the visual detection rate for a small unmanned aircraft system by an aware pilot when transitioning from an instrument approach to visual landing?

- What is the mean distance at which a small unmanned aircraft system can be detected by an aware pilot when transitioning from an instrument approach to visual landing?

- What factors affect visual detection of small unmanned aircraft systems by pilots?

\section{Literature Review}

Several prior studies evaluated the complex problems associated with pilot spotting of small unmanned aircraft systems.

\section{Ohio University Study}

In an experimental study conducted at Ohio University, Kephart and Braasch (2010) compared UAS visual detection success rates from both human participants and a mounted sense-and-avoid camera system. Participants flew aboard a Piper Saratoga and attempted to spot a Piper Warrior III aircraft, designed to simulate an unmanned aircraft system. The researchers created a series of head-on and intersecting conflict encounters between the two craft and measured the detection range for both the participants and electronic sense-andavoid system. The study sample of seven pilots were able to detect the conflict aircraft at a mean range of 1.275 SM. Head-on aircraft encounters were detected at a mean range of $1.038 \mathrm{SM}$ and intersecting aircraft encounters were detected at a mean range of $1.511 \mathrm{SM}$. Since the study utilized a full-size aircraft target, the findings have limited applicability to small UAS detection, however, this initial research formulated the basis of many of the methodological and procedural elements used in the current study.

\section{Colorado Agricultural Aviation Association Case Study}

Maddocks and Griffitt (2015) conducted a field test on behalf of the Colorado Agricultural Aviation Association evaluating pilot visibility of small unmanned aircraft systems operating in proximity to agricultural application operations. During the test, participants flying four fixed-wing aircraft $(2 \mathrm{x}$ Cessna T188C; 2 x AT402B) and one Robinson R44 helicopter were instructed to fly overhead five private fields and conduct a visual survey for obstacles and other hazards. One field did not contain any hazards, two fields contained an Agribotix Enduro (6 lb. quadrotor sUAS) inflight, and the final two fields contained marked ground tarps indicating the presence of UAS activity. While all pilots noted the ground markings, only one fixed-wing pilot briefly spotted a sUAS inflight, when the sun momentarily reflected off the aerial vehicle. The R44 
pilot was able to successfully spot the sUAS in both test fields. Participants suggested that the sUAS craft were significantly more difficult to see than anticipated. While these results did not provide useful quantitative data, the qualitative findings validate subsequent research codifying the difficulties in spotting unmanned aircraft inflight. Additionally, the authors adapted selected methodological elements from this study - particularly the inclusion of a control pass, in which no sUAS was inflight, to ensure validity of the pilot-reported sightings.

\section{Oklahoma State University Studies}

The authors initiated a series of sUAS visibility studies beginning in 2016 . The initial research project evaluated the adequacy of vision for detection, identification, collision recognition, and evasion decision-making (Loffi et al., 2016). Using a mixed methods field experiment, the researchers assessed the ability of 20 pilot participants flying a C-172 to spot a fixed-wing Anaconda sUAS and Iris quadrotor sUAS on predefined intercept courses during daylight VMC. Participants successfully detected the Anaconda sUAS during $84.2 \%$ of the intercepts at a mean range of .49 SM: the Iris sUAS was detected during $36.8 \%$ of intercepts at a mean range of less than $.05 \mathrm{SM}$. The study concluded that based on the sighting distances, coupled with the speed of most general aviation aircraft, most pilots would be unable to successfully perform an evasive maneuver to avoid a collision, based on the FAA's Aircraft Identification and Reaction Time Chart (FAA, 2016).

In a subsequent study, the authors assessed the effectiveness of pilot visual detection of sUAS equipped with high-intensity strobe lighting during daylight VMC (Wallace et al., 2018). Using similar methodology to the Loffi et al. (2016) study, the authors conducted a visibility field experiment with sample of 10 pilots who encountered a series of strobe light-equipped quadrotor sUAS on intercept courses. The sUAS was successfully detected during 3 of the 39 completed intercepts $(n=7.7 \%)$, with the detection distance highly variable ranging from .15 SM to $2.42 \mathrm{SM}$. The authors reported the findings were inconclusive, and not able to definitively support that strobe lighting improved sUAS visibility during daylight visual meteorological conditions.

\section{Methodology}

This study used a mixed methods research approach, with qualitative and quantitative elements. This research methodology was adapted, with only minor changes based on Loffi et al. (2016) and Wallace et al. (2018). Participants were purposefully sampled from certificated pilots recruited from a Part 141 collegiate flight training program in the Midwestern U.S. This research was approved by the 
Oklahoma State University Institutional Review Board on April 15, 2019, Protocol \#ED-18-68.

\section{Procedure}

Participants were asked to perform a simulated instrument approach in a C-172S equipped with a G-1000 avionics suite, flown inbound to the Unmanned Systems Research Institute airfield, a UAS test site with a fabric surface runway. The approach was designed to emulate a standard $3^{\circ}$ precision-approach glide path starting at the Final Approach Fix (FAF), 5 NM north of the airfield at 2,700 feet MSL (1,700 feet AGL), with a Decision Height of 1,250 feet MSL (250 feet AGL). The Minimum Safe Altitude (MSA) was also 250 feet AGL.

The test site was located within Class $\mathrm{G}$ airspace, and operating under a COA for UAS operations within a $1 \mathrm{NM}$ radius from the surface to 2,500 $\mathrm{ft}$ AGL from the facility (see Figure 4). Each participant flew five approaches, in succession. All flights were to be conducted during daylight hours, during visual meteorological conditions.

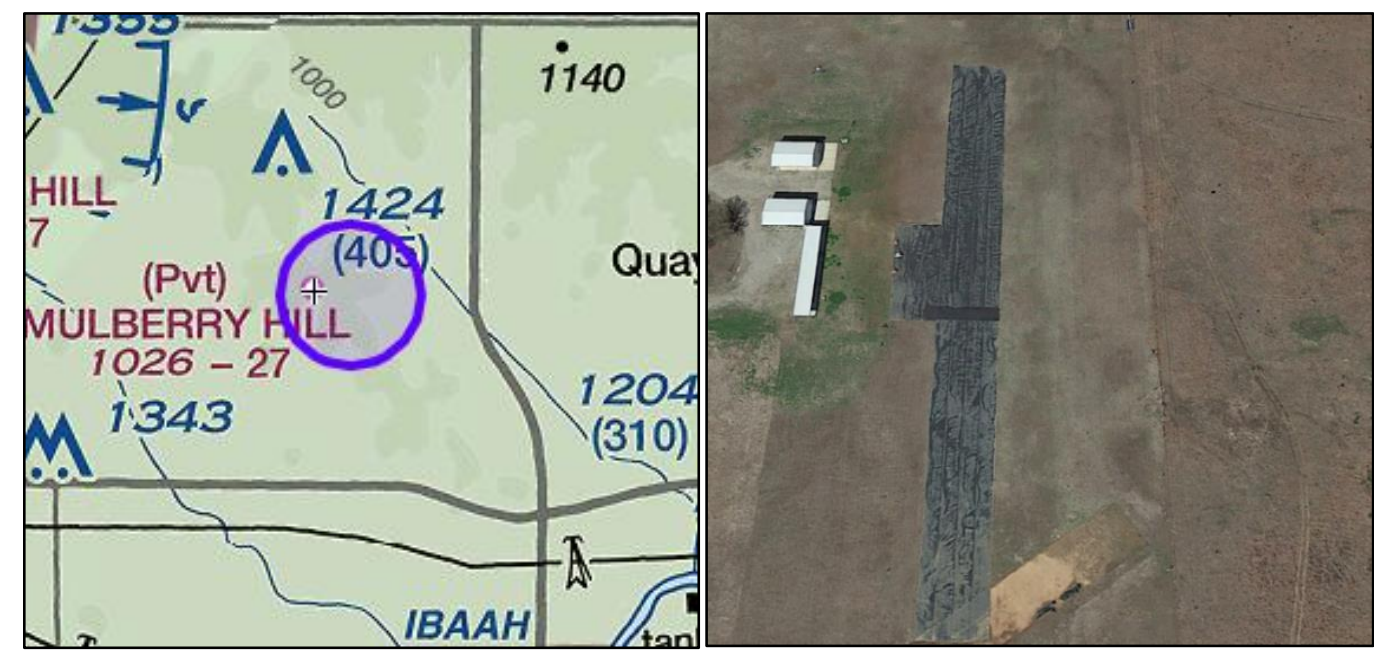

Figure 4. [Left] Unmanned Systems Research Institute COA and surrounding airspace (Excerpt from Dallas Sectional aeronautical chart). [Right] Aerial depiction of Unmanned Systems Research Institute airfield (derived from Google Earth; view looking from South to North).

During each approach a small unmanned aircraft system performed scripted maneuvers on a perpendicular axis at a distance of 1,000 ft from airfield along the approach corridor. All UAS flights were conducted at $50 \mathrm{ft}$ AGL. The approach MSA afforded a 200-ft safety margin between the unmanned aircraft and manned aircraft, however, pilots were advised they could execute a go-around or other evasive maneuver, if they felt safety had been compromised. 
The airfield approach setup was purposefully designed to replicate a standard U.S. precision final approach path of $3^{\circ}$ from the FAF, 5 NM from the touchdown point. The methodology was designed to have the participants execute a safe, familiar profile in visual conditions starting at the FAF. This $3^{\circ}$ FAF 5 NM standard applies to all U.S. ILS, GPS, PAPI and VASI vertical guidance system, unless otherwise noted in the FAA's Digital Chart Supplements or IFR Approach plates. While very much an IFR-sounding methodology, the design was not intended to replicate restricted IFR visibilities typically encountered when needing a precision approach. The design was intended to stabilize the aircraft on approach and allow the participant to concentrate on the forward-view sight picture of the runway all the way to the simulated Decision Height (Missed Approach Point) altitude.

When executed properly, the visual sight picture of the participant would immobilize the runway in the aircraft windshield. The only change in the sight picture the participant was designed to see during the execution of the visual approach was the increasing size of the immobilized runway.

An airborne researcher accompanied each flight, stationed in the aft seat. This individual was responsible for recording pilot sighting times, reported verbally on the intercom. Upon conclusion of each pass, the researcher would also document participant qualitative observations, comments, or impressions.

\section{UAS Procedure}

Researchers elected to use a DJI Phantom IV (white quadrotor) UAS for the experiment. This selection was made due to the ubiquitous nature of DJI platforms operating within the NAS, as well as UAS fleet availability. It is estimated that DJI platforms comprise approximately $74 \%$ of the market share for consumer UAS within the United States (Skylogic Research, 2018).

The researchers included the following UAS maneuvers, implemented randomly to ensure reliability (Note: all aircraft approaches were conducted along a southbound trajectory):

- Control Pass--No UAS in flight (implemented to screen false positive sightings)

- Static-Starboard-UAS flew out to a distance of 1,000 feet north of the airfield and performed a stationary, hovering maneuver orientated 100 feet east of the approach course.

- Static-Port-- UAS flew out to a distance of 1,000 feet north of the airfield and performed a stationary, hovering maneuver orientated 100 feet west of the approach course.

- Maneuvering-UAS flew out to a distance of 1,000 feet north of the airfield and transitioned laterally crossing back and forth up to 200 feet left and right of the approach course 


\section{Safety Protocols}

To further ensure safety during the experiment, a safety pilot was stationed in the co-pilot's seat and instructed to assume command of the aircraft if he determined flight safety had been compromised. Safety pilots were all experienced Certified Flight Instructors and were considered non-participants for experimental purposes. Safety pilots were also provided a sequential list of the UAS maneuver sets, and furnished access to an isolated radio to perform safety coordination with UAS operators on the ground. The pre-planned response to a UAS flyaway, potential real-world collision threat, or other unforeseen emergency was for the initiating individual (any individual that noticed the safety issue) to call a "knock it off" over the radio and the safety pilot to initiate a climbing evasive maneuver to exit the UAS operating area.

\section{Assumptions}

The researchers presumed the following conditions during the experiment (as adapted from Wallace et al., 2018):

- The skill and experience of participants was reasonably representative of general aviation pilots of equivalent certificate levels.

- Participants honestly and accurately self-reported visual acuity.

- Positional and altitude data from the C-172/S avionics suite and Phantom IV telemetry were assumed to be accurate.

- Participants reported sUAS sightings honestly, accurately, and without substantive delay. (Note: honest reporting was also validated through the use of a random control intercept.)

\section{Limitations}

The researchers were constrained by the following limitations (also adapted from Wallace et al., 2018).

- The high cost of conducting flight experiments rather than simulation limited the scope and number of participants. The limited number of participants prevented collection of adequate data points to conduct statistical inference or generalizability testing.

- The experiment was supposed to include two maneuvering passes, with one originating from the port side of the aircraft, and the other from the starboard side. Unfortunately, an execution error resulted in the one of these pass types being randomly selected. This explains the inconsistency in the number of pass types for each participant. The authors reported this 
inconsistency in the dataset by describing this intercept as the random pass.

\section{Findings and Discussion}

The study was carried out from July 8-11, 2019, with 10 pilots participating. Pilot demographic information and self-reported visual acuity are presented in Table 1. The researchers loosely associated advanced pilot certificates with participants' experience in see and avoid procedures.

Table 1

Participant Aeronautical Demographics

\begin{tabular}{cccc}
\hline Participant & FAA Pilot Certificate(s) & $\begin{array}{c}\text { Medical } \\
\text { Certificate }\end{array}$ & Reported Vision \\
\hline 1 & CP, IR & $1^{\text {st }}$ Class & $20 / 20$ \\
2 & CP, IR, CFI & $1^{\text {st }}$ Class & $20 / 20$ \\
3 & CP, IR, CFI & $1^{\text {st }}$ Class & $20 / 20^{*}$ \\
4 & PP, IR & $1^{\text {st }}$ Class & $20 / 20$ \\
5 & CP, IR, CFI & $3^{\text {rd }}$ Class & $20 / 20$ \\
6 & PP, IR & $1^{\text {st }}$ Class & $20 / 20$ \\
7 & PP, IR & $1^{\text {st }}$ Class & $20 / 20$ \\
8 & CP, IR, CFI & $1^{\text {st }}$ Class & $20 / 20$ \\
9 & CP, IR, CFI & $1^{\text {st }}$ Class & $20 / 20$ \\
10 & CP, IR & $1^{\text {st }}$ Class & $20 / 20$ \\
\hline
\end{tabular}

Note. $(\mathrm{PP}=$ Private Pilot; IR = Instrument Rating; $\mathrm{CP}=$ Commercial Pilot; $\mathrm{CFI}=$ Certified Flight Instructor). * Indicates with corrective lenses.

Flights were conducted between the hours of 7:30 AM-12:30 PM, local time in VMC. Weather data was collected to determine possible environmental impacts to visibility (see Table 2 ).

The airborne researcher reported that low-lying haze decreased visual clarity during the July 8-10 flights. This condition was reportedly not present on July 11 , which may have contributed to improved sighting rates. 
Table 2

Local Weather Information at Onset of Participant Flights

\begin{tabular}{ll}
\hline P\# & \multicolumn{1}{c}{ METAR Observation } \\
\hline 1 & KSWO 081300Z AUTO 23004KT 10SM CLR 25/21 A2995 RMK T02500210 MADISHF \\
2 & KSWO 081430Z AUTO 00000KT 10SM CLR 29/20 A2997 RMK T02900200 MADISHF \\
3 & KSWO 081625Z AUTO 19011KT 10SM FEW100 32/20 A2996 RMK T03200200 \\
& MADISHF \\
4 & KSWO 090753Z AUTO 17006KT 10SM CLR 24/22 A2988 RMK AO2 SLP103 \\
& T02440217 \\
5 & KSWO 091435Z AUTO 17010KT 10SM CLR 28/21 A2993 RMK T02800210 MADISHF \\
6 & KSWO 101300Z 19005KT 2SM HZ CLR 28/24 A3000 RMK AO2 VIS 1V4 T02830239 \\
7 & KSWO 101430Z AUTO 19005KT 10SM CLR 31/23 A3002 RMK T03100230 MADISHF \\
8 & KSWO 111253Z 01005KT 10SM SCT065 24/18 A3013 RMK AO2 SLP187 T02440178 \\
9 & KSWO 111430Z AUTO 05011KT 10SM CLR 28/17 A3012 RMK T02800170 MADISHF \\
10 & KSWO 111605Z AUTO 05009KT 10SM CLR 31/16 A3011 RMK T03100160 MADISHF \\
\hline
\end{tabular}

Note. Data derived from archival Oklahoma ASOS data obtained from Iowa State University, Iowa Environmental Mesonet, https://mesonet.agron.iastate.edu/

\section{Quantitative Data}

Table 3

Sighting Ranges by Intercept Type (feet)

\begin{tabular}{ccccccc}
\hline & & & Static- & Random & Random Pass \\
Participant & Control & Static-SB & P & Moving & Pass & Type \\
\hline P1 & 0 & 0 & 0 & 0 & 0 & Moving \\
P2 & 0 & 0 & 0 & 1086 & 0 & Static-P \\
P3 & 0 & 0 & 0 & 0 & 0 & Moving \\
P4 & 0 & 0 & 0 & 0 & 0 & Moving \\
P5 & 0 & 0 & 0 & 0 & 1585 & Moving \\
P6 & 0 & 0 & 0 & 0 & 0 & Static-P \\
P7 & 0 & 0 & 0 & 0 & 2219 & Moving \\
P8 & 0 & 0 & 1077 & 842 & 1781 & Moving \\
P9 & 0 & 950 & 0 & 1400 & 1615 & Moving \\
P10 & 0 & 0 & 213 & 1488 & 2324 & Moving \\
\hline
\end{tabular}




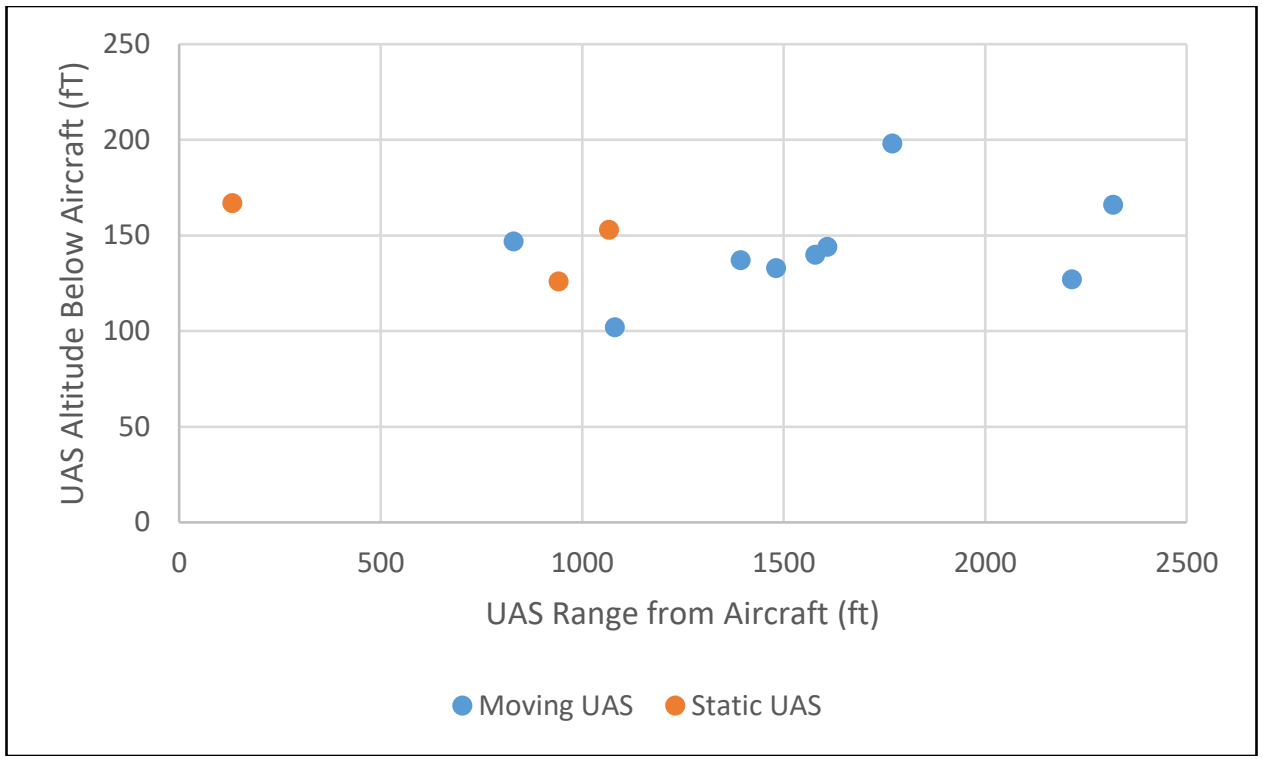

Figure 5. UAS Sightings by Range and Altitude (measured in feet).

Sightings by Intercept Type. Table 3 and Figure 5 present UAS sighting data. Overall, participants spotted the unmanned aircraft on 12 occasions out of a total of 40 possible events ( $n=30 \%$ detection rate). There were no false positive reports during the control pass, indicating participants were likely honest in reporting visual acquisition of the unmanned aircraft. Detections ranged in distance from a minimum of 213 feet to a maximum of 2,324 feet (see Figure 6). 


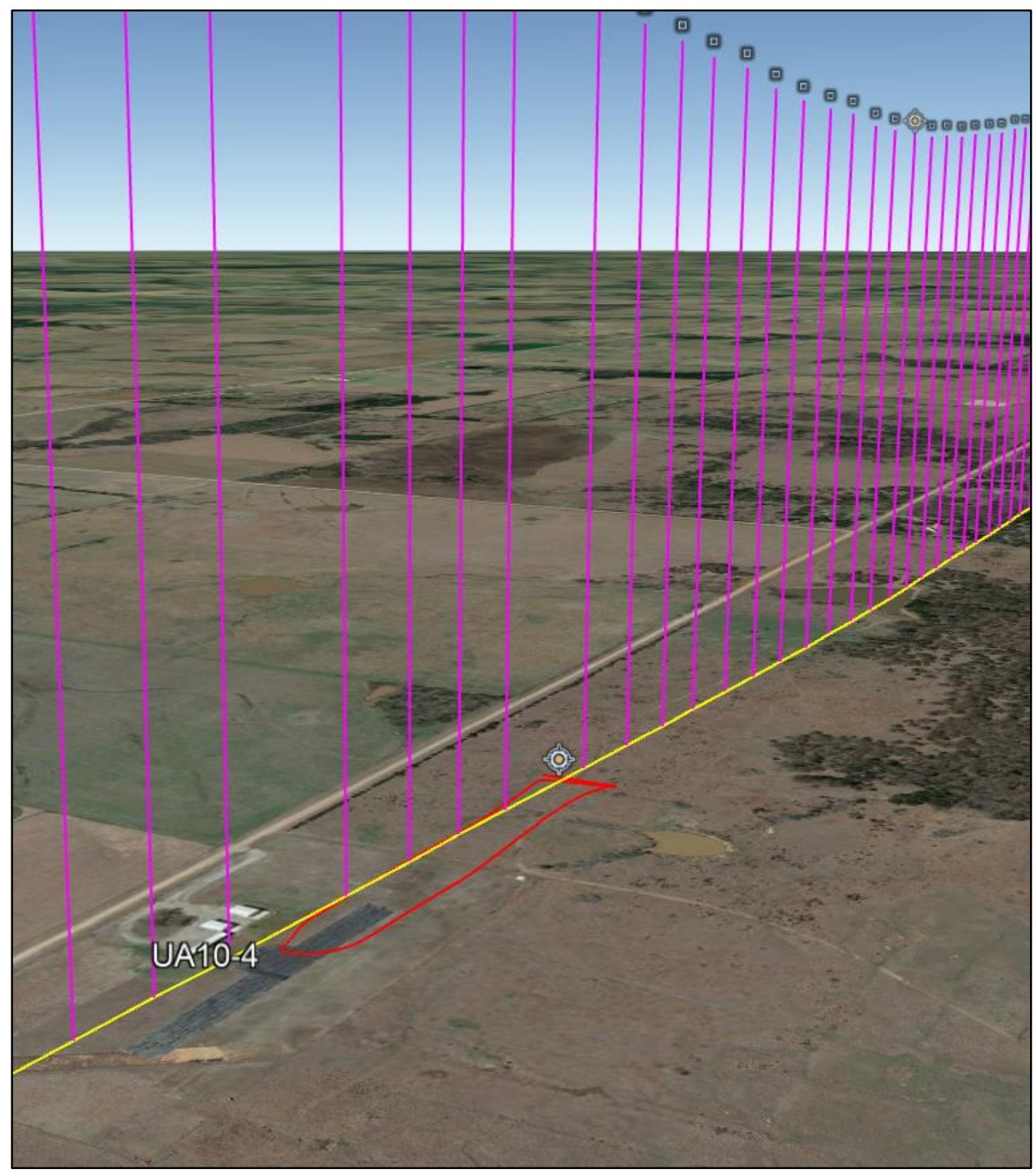

Figure 6. Telemetry plot of UAS sighting by Participant 10 . This intercept depicts the maximum sUAS sighting distance recorded during the experiment, with a detection range of 2,324 feet. Initial detection locations for both the aircraft and sUAS are depicted by the target reticule icon. The sUAS was maneuvering laterally at the time of detection.

The largest proportion of sightings occurred during sUAS moving passes, with 9 sightings out of a total of 18 possible events $(n=50 \%)$. The mean detection range for moving sUAS (excluding null sightings) was 1,593.3 feet. 
This leaves very little margin for a pilot to detect a sUAS, recognize the collision threat, make an evasion decision, and successfully execute an evasive maneuver.

The detection rate for static passes was much lower, with only 3 detections out of 22 possible events, representing a detection rate of $13.6 \%$. Static detections were slightly higher when the sUAS was positioned on the port side of the aircraft. This makes logical sense, due to the fact that the participant was positioned in the left seat of the aircraft, giving them easier access to view the left portion of the windscreen, as well as out the left pilot window. Nevertheless, the lack of additional data makes this observation anecdotal rather than conclusive. The mean detection distance for static sUAS targets was 746.7 feet, nearly half the distance of moving sUAS detections.

Ground haze during the July 8-10 flights may have played a significant role in obscuring sUAS detection, which may explain the uptick in participant sightings that occurred on July 11.

Researchers evaluated the vectors at which pilots made successful sightings. Moving sUAS sightings were exclusively detected within a small visual cone extending $0^{\circ}-5^{\circ}$ right of center and $5^{\circ}-10^{\circ}$ downward from the horizon. Static sUAS targets were detected more peripherally. Results are presented in Table 4 and Figure 7.

Table 4

Successful sUAS Sightings Data

\begin{tabular}{lcccccc}
\hline Part / & $\begin{array}{c}\text { Intercept } \\
\text { Intercept }\end{array}$ & $\begin{array}{c}\text { Altitude } \\
\boldsymbol{\Delta}(\mathrm{ft})\end{array}$ & $\begin{array}{c}\text { Lateral } \\
\text { Dist } \\
(\mathrm{ft})\end{array}$ & $\begin{array}{c}\text { Slant } \\
\text { Range } \\
(\mathrm{ft})\end{array}$ & $\begin{array}{c}\text { Horizontal } \\
\text { Aspect Angle } \\
\left({ }^{\circ}\right)\end{array}$ & $\begin{array}{c}\text { Vertical } \\
\text { Aspect Angle } \\
\left({ }^{\circ}\right)\end{array}$ \\
\hline P2-4 & Moving & 102 & 1081 & 1086 & 5 & 5 \\
P5-5 & Moving & 140 & 1579 & 1585 & 0 & 5 \\
P7-4 & Moving & 127 & 2216 & 2219 & 3 & 5 \\
P8-3 & Moving & 147 & 829 & 842 & 1 & 10 \\
P8-4 & Static & 153 & 1066 & 1077 & -4 & 8 \\
P8-5 & Moving & 198 & 1770 & 1781 & 4 & 6 \\
P9-2 & Moving & 137 & 1393 & 1400 & 1 & 6 \\
P9-3 & Static & 126 & 942 & 950 & 8 & 8 \\
P9-5 & Moving & 144 & 1608 & 1615 & 4 & 5 \\
P10-1 & Moving & 133 & 1482 & 1488 & 1 & 5 \\
P10-2 & Static & 167 & 132 & 213 & -44 & 52 \\
P10-4 & Moving & 166 & 2318 & 2324 & 3 & 4 \\
\hline
\end{tabular}




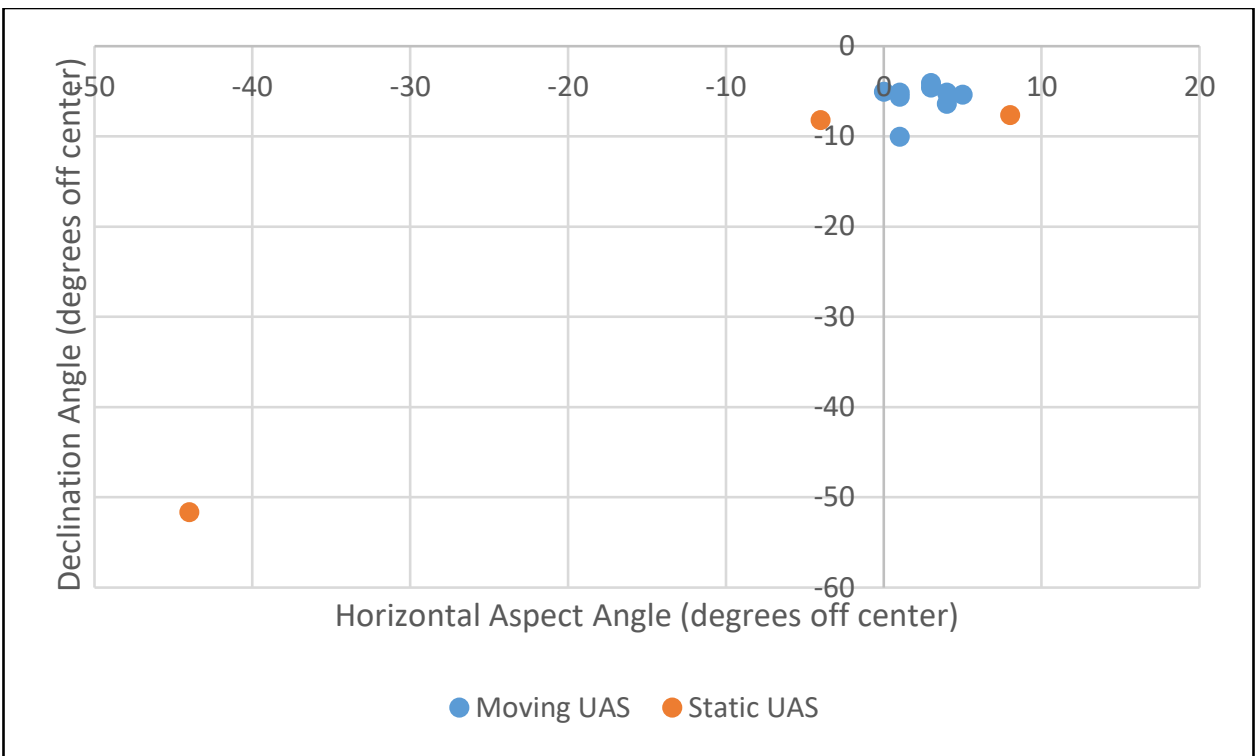

Figure 7. Pilot Visual Aspect at Time of Sighting.

\section{Qualitative Data}

The participants provided a plethora of observations, comments, and impressions from their experience. An evaluation of participant comments revealed several trends.

Spotting the sUAS was difficult. Six of the 10 participants commented about how difficult it was to detect the sUAS. Participant \#2 called it a "very small speck moving left to right in the glidepath." Participant \#3 suggested, "you won't see it unless you look at the right spot at the right time." According to participant \#5, "I feel I have good vision. If there is a UAS there, it is very hard to see." Participant \#7 commented, "it makes me kind of nervous knowing it [sUAS] is there but not seeing it." Participant \#8 alluded, "in a faster airplane it would be hard to spot, if not alerted...would not be easy to see. Being hyper alert contributed to seeing the UAV." Participant \#9 stated "[the UAS was] difficult to see..." Participant \#10 confirmed, "It was a lot harder [to spot] than first thought. If not alerted as in the research, it would have been harder still."

These observations are also supported by the quantitative data. The conditions of the experiment likely improved sightings beyond what would normally be realized in operational settings. First, participants were made aware of the presence of a sUAS, encouraging greater situational awareness and focus outside the aircraft. Additionally, atmospheric conditions - with the exception of the aforementioned haze-were generally favorable with a reported visibility of 10 SM during all but one pass (see Table 2). Finally, the experiment was 
conducted in uncongested Class G airspace, inducing very few operational distractions for the pilot participant.

Wallace et al. (2018) reflected these same findings in a similar, prior experiment where " $90 \%$ [of participants] indicated the sUAS was 'difficult' or 'very difficult' to see. Forty percent of participants stated they had 'low' or 'no' confidence in their ability to detect the sUAS" (pp. 64-5).

Contrast. Half of the participants commented about the importance of contrast between the sUAS and background. Participant \#4, "If you have blue behind objects [sky] it is much easier to see than if you have green [ground]." Conversely, Participant \#8 disagreed stating, "the contrast of the white UAV to the green grass...brought my attention to the UAV. Participant \#9 also commented about the white UAV color having strong contrast with the green background. Participant \#10 agreed stating, "I was attracted by the white color against the green grass and movement." Participant \#6 suggested the addition of lights or high-visibility coloration to improve contrast. The recommendations for high contrast was also a finding reflected in Loffi et al. (2016).

Moving sUAS are easier to spot. Four of the 10 participants indicated that when the sUAS was in motion it became slightly easier to spot. Participant \#7 stated, "[sUAS] motion helped to detect. If sitting still it would be hard to see." Participant \#8 observed, "movement first brought my attention to the UAV." Participant \#9 indicated, "It was difficult to see except for movement." Participant \#10 echoed these observations, saying, "The way the UAV moved confirmed it was not a bird...movement attracted attention." This finding is notable since in the Loffi et al. (2016) study, researchers recorded improved visual detection of fixed wing sUAS platform over rotorcraft sUAS. This was initially thought to be attributed to the high-visibility wing-flash produced when the fixed-wing craft maneuvered, however, this effect may actually be more resultant of the relative motion of the sUAS to the observer.

Misidentification. Two participants indicated that despite being aware of the presence of a sUAS, they did not initially identify the spotted object correctly. Participant \#9 identified the sUAS as a possible fixed-wing aircraft, "it appeared to have a solid wing as it moved left to right...glancing at the UAV and flying the airplane gave me the impression the UAV was a fixed-wing." Participant \#10 similarly stated, "it took a few moments to recognize what I was looking at, which was somewhat surprising."

UAS more likely to be seen from front and left aspects. Researchers anticipated more comments about the positioning of the participant in the aircraft relative to the sUAS aspect, however, only one comment was recorded. Participant \#1 said, "If it's off to the side I will not see it. I am concentrating straight ahead. Left is easier, since looking right requires me to see up and over the dash." Nevertheless, the earlier-presented quantitative data suggests higher 
successful detections within a $12^{\circ}$ lateral and $5^{\circ}$ vertical wedge of center. Loffi et al. (2016) also identified the tendency of participants to centrally focus scanning efforts, with $10 \%$ of the participants not performing full-range visual scanning and instead focusing between the "11:00-2:00 positions" (p. 18).

\section{Image/Video Data}

The researchers collected a number of images and videos from the experiment that highlight various findings and reported concepts. While not all elements fall within the direct scope of the study, the exploratory nature of the research made a compelling case for reporting these observations.

Several images of the various intercepts were taken from the ground perspective. It is notable that in several cases these images generated the illusion that the aircraft was much closer in proximity and altitude than reality (see Figure 8 ). In these cases, the ground observer's visual angle and perception places the closer sUAS in direct visual line with the aircraft. An optical illusion is created due to the tendency of observers to subconsciously compare the objects as relatively comparable in size. This finding was also noted in Vance et al. (2017). The size of the sUAS (excluding propellers) measures a width of $289.5 \mathrm{~mm}(.95$ $\mathrm{ft}$ ) and height of $196 \mathrm{~mm}(.64 \mathrm{ft})$, whereas the C-172/S measures approximately 36 $\mathrm{ft}$ wide and $9 \mathrm{ft}$ high, respectively (Cessna, 2012; DJI, 2019). This effect is modeled in Figure 8.

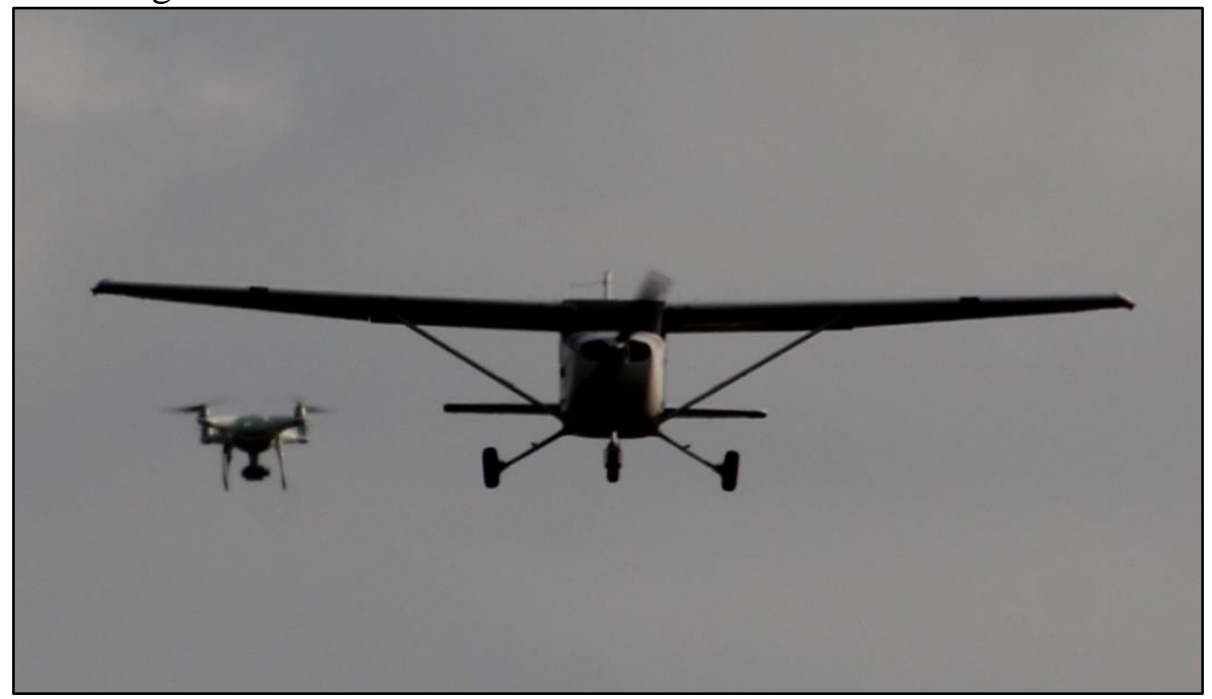




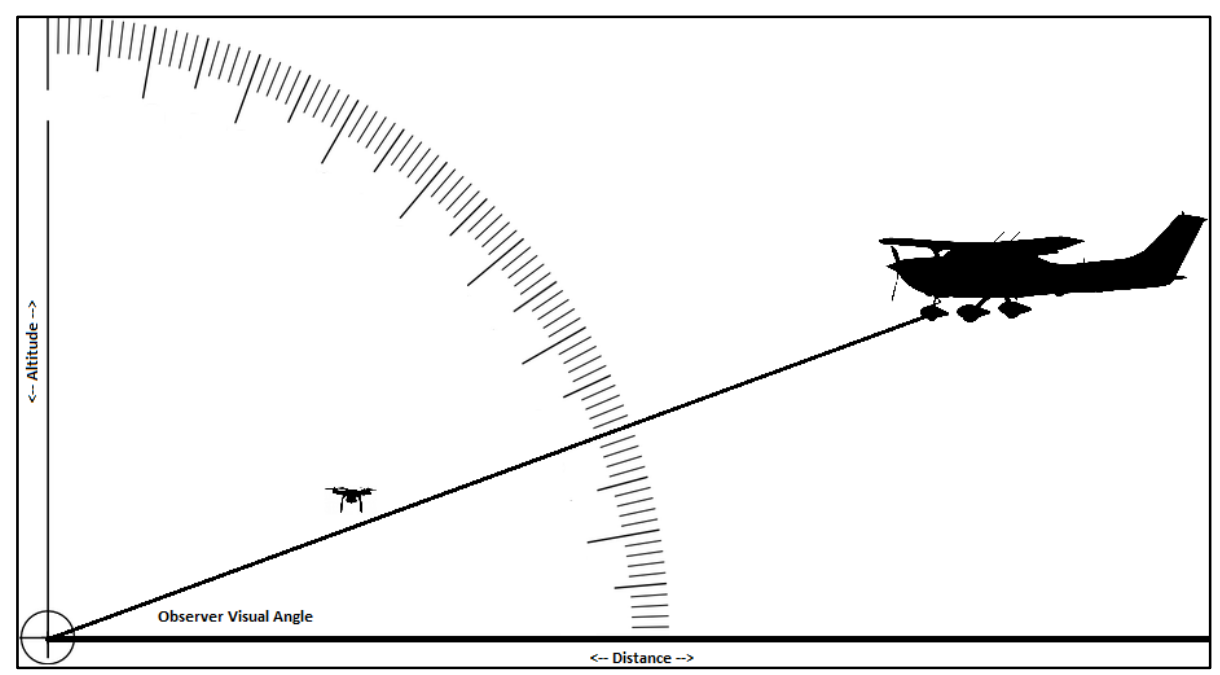

Figure 8. [Top] Image of sUAS approach encounter (ground perspective). This view is comparable to what a Remote Pilot or Visual Observer would perceive. [Bottom] Note the size differential between the aircraft and sUAS. Because the sUAS is closer to the observer, it appears larger and thus seems perceptively closer to the aircraft. Additionally, because the sUAS and the aircraft are along the same visual plane relative to the observer, the sUAS appears to present collision threat, whereas, there is clearly an altitude separation between the two.

Data was also collected from the Phantom IV to better understand the Remote Pilot's perspective with regard to aircraft collision avoidance. Figure 9 depicts time-delayed screen captures from the Phantom IV's electro-optical camera taken at 30-, 10-, and 2-seconds prior to the aircraft intercepting the sUAS. These images correspond to lateral ranges of approximately 5,063 ft; 1,688 $\mathrm{ft}$; and $338 \mathrm{ft}$, respectively. The aircraft was extremely difficult to detect at long range. The experimental aircraft was equipped with wig-wag LED landing lights, which were activated during the experiment. Observation of the alternating flash pattern was only faintly recognizable; and, the aircraft is almost indiscernible at the 30 -second interval. At the 10-second interval, the wig-wag lights are fairly obvious and the aircraft form is generally discernable. Two seconds prior to intercept, the aircraft's individual structural elements are easily spotted; and, wigwag light pattern becomes more difficult to see as the aircraft transitions overhead. 
International Journal of Aviation, A eronautics, and Aerospace, Vol. 6 [2019], Iss. 5, Art. 12

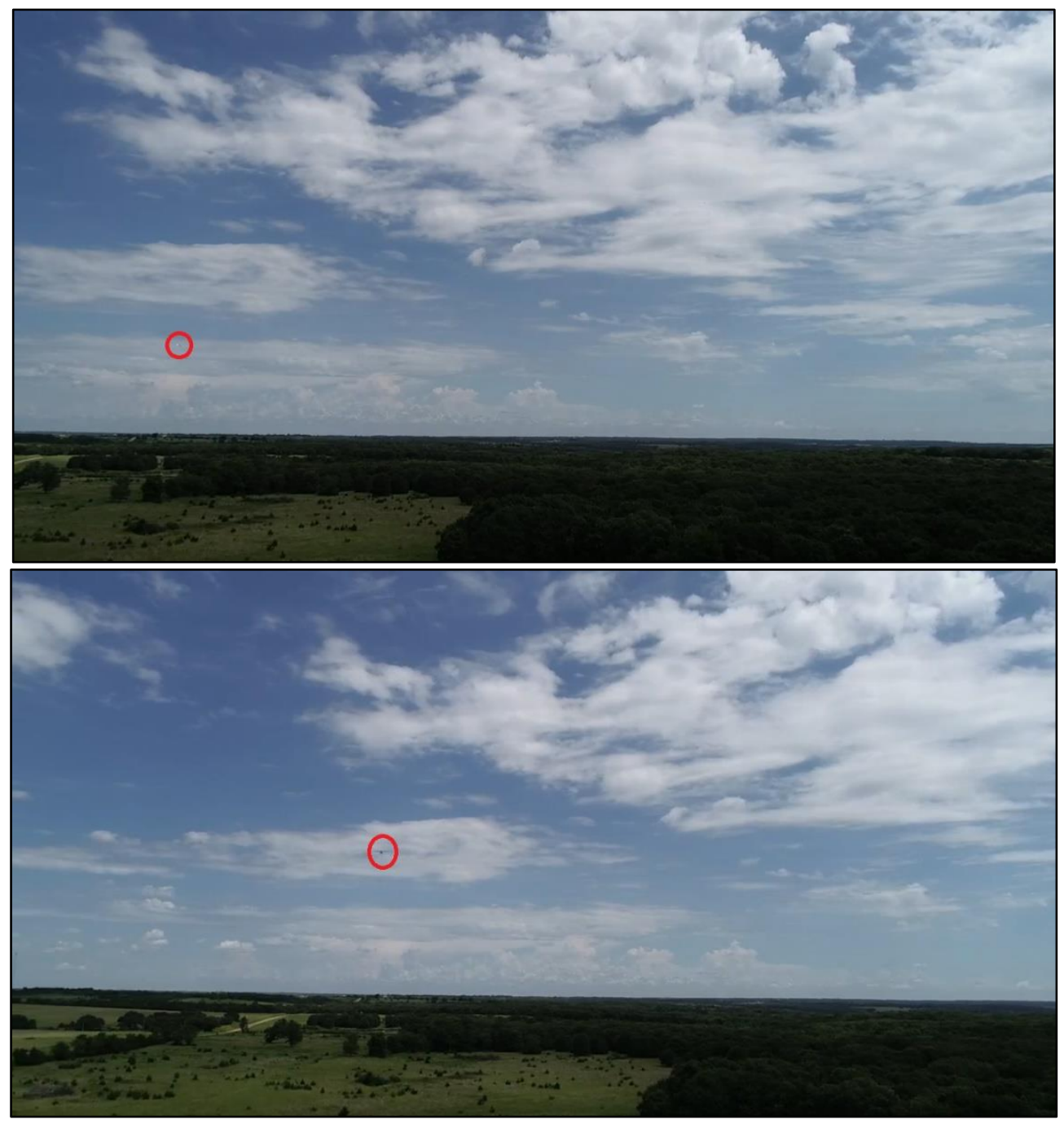




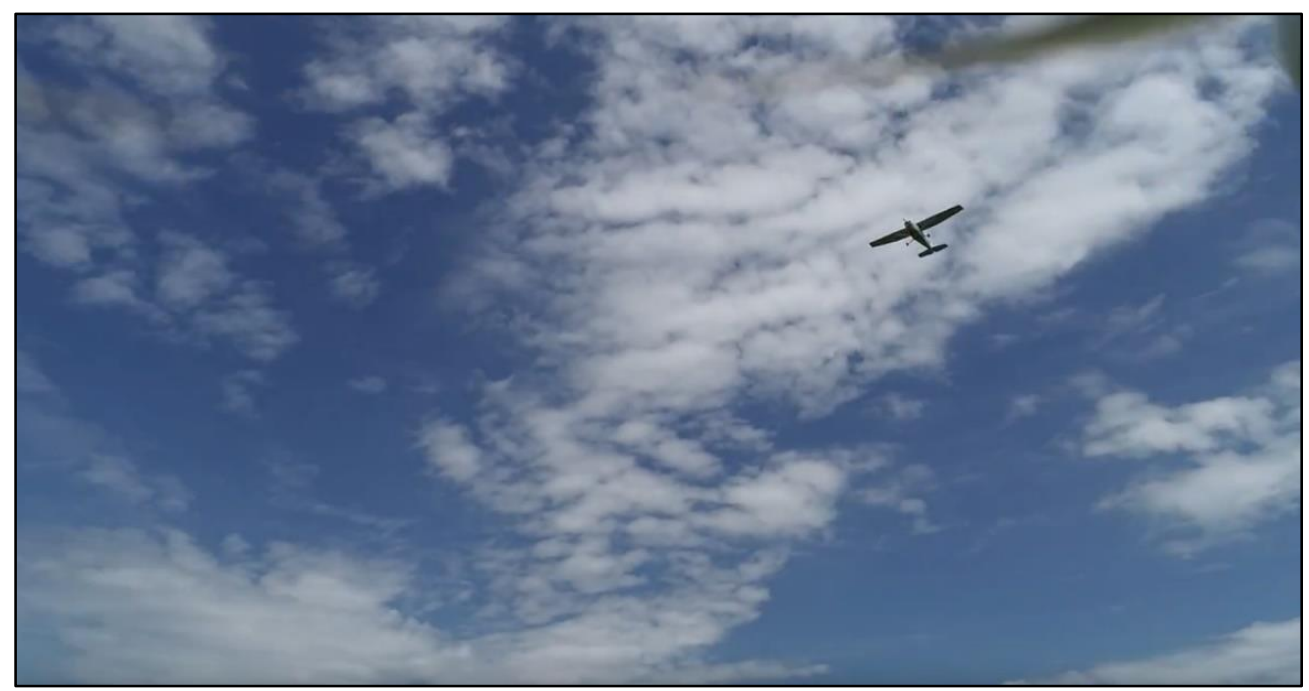

Figure 9. Excerpts from sUAS video taken prior to aircraft overflight of sUAS with aircraft highlighted in red: (Top) 30 seconds prior; (Middle) 10 seconds prior; (Bottom) 2 seconds prior. Long-range identification was nearly impossible without relying on spotting the aircraft's wig-wag LED landing lights. Full video available at: https://commons.erau.edu/ijaaa/vol6/iss5/12/

Video from a camera mounted on the aircraft's tie-down ring captures an approximation of the pilot's visual perspective of a sUAS encounter. It should be noted that a pilot's view is likely to be obscured by obstacles such as the instrument panel, aircraft structure, or even an unclean windscreen-these conditions all make sUAS detection more difficult than presented in the video. Time-capture images from the external camera shown in Figure 10 reveal the relatively small size of the sUAS and accompanying difficulty in successfully detecting the sUAS. The video from Figure 9 corresponds to aircraft and sUAS telemetry presented in Figure 11. 


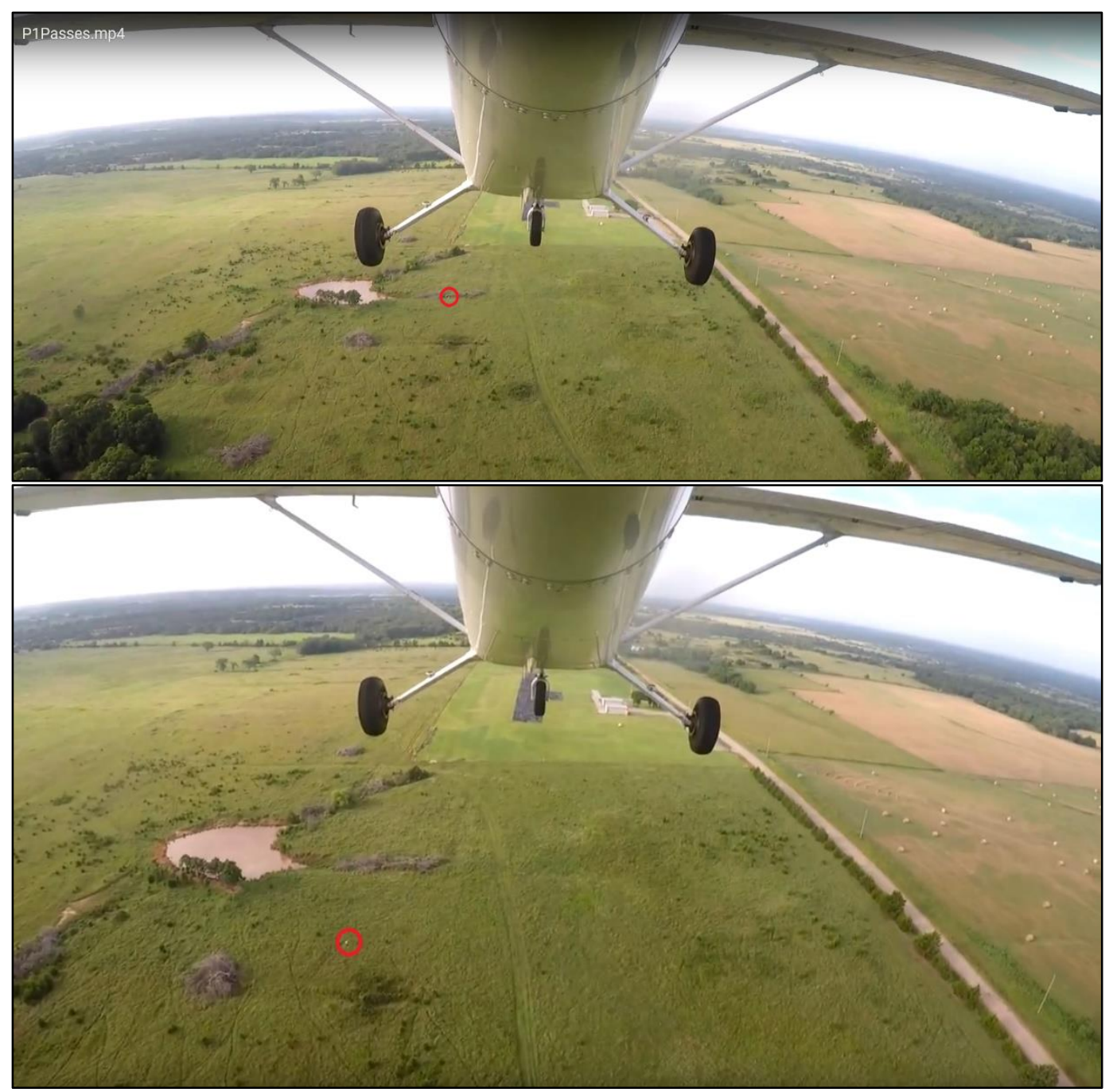

Figure 10. Excerpts from externally-mounted video camera taken during Participant 1 , Intercept 2 . Note the relatively small size makes the sUAS extremely difficult to detect. The participant did not detect the sUAS during this pass. Full video available at: https://commons.erau.edu/ijaaa/vol6/iss5/12/ 


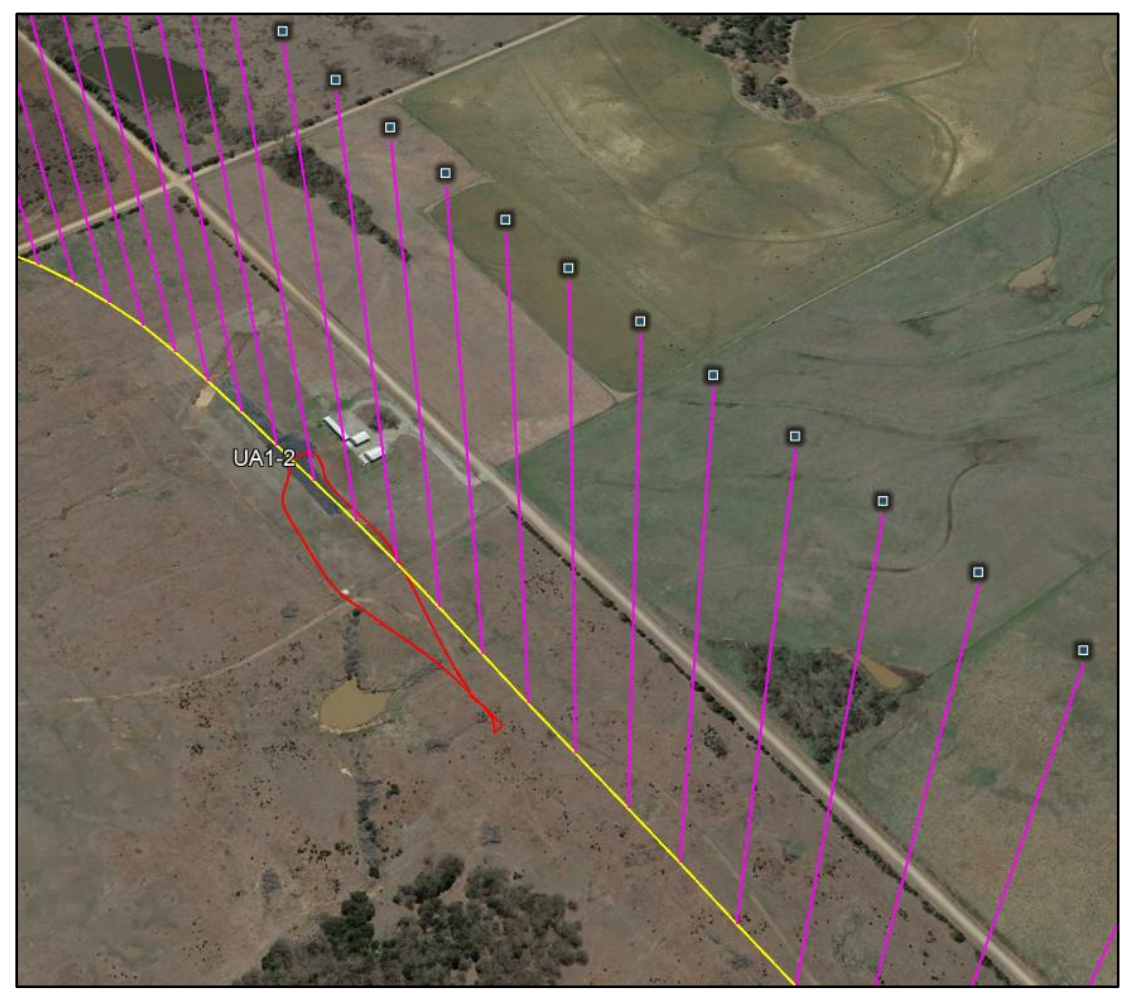

Figure 11. Aircraft/UAS telemetry overview presented in Google Earth. Aircraft ground track presented in yellow, with altitude indicated by raised plots; sUAS flight track depicted in red. The participant did not detect the sUAS during this pass. Data derived from Participant 1, Intercept 2. This telemetry corresponds to video data presented in Figure 9.

\section{Conclusions and Recommendations}

\section{Visual Detection Rate}

Participants detected the sUAS during 12 out of 40 possible events, resulting in an overall detection rate of $30.0 \%$. Moving sUAS were detected during 9 out of 18 possible events, resulting in a detection rate of $50.0 \%$. Static sUAS were detected during only 3 out of 22 possible events, yielding a detection rate of $13.6 \%$. This data seems to indicate that detection rate is substantially improved when the sUAS is in motion.

\section{Detection Distance}

Overall, the mean detection distance for all passes (excluding failed sightings) was 1,382 ft. Mean detection distance for moving sUAS was 1,593 ft. The mean detection distance for static sUAS was $747 \mathrm{ft}$. Again, this data seems to suggest that moving sUAS are easier to spot than static ones. 


\section{Factors Affecting Visual Detection}

Participants generally indicated that spotting the sUAS was much more difficult than originally anticipated. Despite favorable visual conditions, participants were still challenged to successfully spot airborne sUAS. While participants indicated that moving and high-contrast sUAS targets were easier to detect, efforts should be made to employ scanning strategies to spot static and low-contrast targets, as well. This suggests a possible need for emphasis in scanning training to adequately prepare pilots to employ proper techniques to maximize visual detection. This could also include an effort to make manned pilots more aware of the need for vigilant scanning to detect unmanned aircraft when flying at low altitude or in areas of known sUAS operations.

Small UAS operators should be cognizant of the challenges associated pilot detection of their platforms. Steps should be taken by the sUAS Remote Pilot to maximize the conspicuity of their platforms, such as using high-contrast UAS colors, performing regular maneuvers, or other strategies to make their operation as visible as possible.

Both the sightings data and participant comments suggest that pilot scanning tends to concentrate within the central rather than peripheral fields of view. Small UAS operating near the approach corridor, yet outside a pilot's field of view or concentration could easily and quickly penetrate the approach corridor, thereby posing an immediate and immutable collision threat. Pilots need to effectively scan the approach path to ensure clearance, but also should not forget to regularly check the periphery for possible airborne threats outside of the normal, centralized field of view.

\section{Evasive Action Impact}

This research highlights that the relatively high closure rate coupled with the short detection distances between the aircraft and sUAS leaves little (if any) margin for evasive action. Even when the aircraft is configured for its slowest approach speed (approximately $65 \mathrm{kts} / 74.8 \mathrm{mph}$ ) and the sUAS is static, the available response time would be approximately 14.5 seconds, based on the mean detection distance of $1,593 \mathrm{ft}$. This leaves a margin of only 2 seconds above the FAA's recommended minimum reaction time required for evasion (FAA, 2016). Even at the maximum detection range of 2,324 ft recorded during the experiment, the available response time would be only 21.2 seconds. The aforementioned condition is the best case scenario. A pilot's available reaction time would be considerably less if the aircraft approach speed were higher or the unmanned aircraft was closing on the aircraft's flight path. This finding is generally similar to the findings contained in Loffi et al. (2016). Succinctly, UAS sightings in the final moments of an approach present a significant risk to flight safety. An aircraft 
on a stabilized approach to landing will be at low altitude, configured for a low airspeed. These conditions make abrupt, evasive maneuvers particularly hazardous.

\section{Future Research}

In a future research project, the authors intend to conduct an experiment attaching a UAvionics Ping - an ADS-B (out) device - to a sUAS to determine if pilots can effectively correlate, spot, and evade sUAS displayed on electronic situational awareness and collision avoidance equipment. The objective of this research is to determine how pilot access to real-time UAS Remote Identification data could improve pilot situational awareness and midair collision avoidance. 


\section{References}

Aviation Safety Reporting System. (2019). ASRS screening data: Unmanned aerial vehicle (UAV) reports (Search Request \# 7283). Moffett Field, CA: Author.

Cessna Aircraft Company. (2012). Skyhawk model 172S: Specification and description. Wichita, KS: Author.

DJI. (2019). Phantom 4 specs. Retrieved from https://www.dji.com/phantom4/info

Federal Aviation Administration. (2016). Pilots' role in collision avoidance [Advisory Circular, AC 90-48D]. Retrieved from https://www.faa.gov/ documentLibrary/media/Advisory_Circular/AC_90-48D.pdf

Federal Aviation Administration. (2019a). Safe and secure operations of small unmanned aircraft systems. Retrieved from https://www.regulations.gov/ document?D=FAA-2018-1086-0001

Federal Aviation Administration. (2019b). UAS sightings report [database]. Retrieved from https://www.faa.gov/uas/resources/public_records/ uas_sightings_report/

Gettinger, D. \& Michel, A.H. (2015). Drone sightings and close encounters: An analysis. Center for the Study of the Drone at Bard College. Retrieved from https://dronecenter.bard.edu/files/2015/12/12-11-Drone-Sightingsand-Close-Encounters.pdf

Kephart, R. J. \& Braasch, M. S. (2010). Comparison of see-and-avoid performance in manned and remotely piloted aircraft. IEEE Aerospace and Electronic Systems Magazine, 25(5), 36-42. doi:10.1109/MAES.2010.5486540

Loffi, J. M., Wallace, R. J., Jacob, J. D., Dunlap, J. C. (2016). Seeing the threat: Pilot visual detection of small unmanned aircraft systems in visual meteorological conditions. International Journal of Aviation, Aeronautics, and Aerospace, 3(3). Retrieved from https://commons.erau.edu/ijaaa/vol3/iss3/13

Maddocks, J., \& Griffitt, G. (2015). Qualitative evaluation of unmanned aircraft visibility during agricultural flight operations. Avion. Limited Access Report obtained from the Colorado Agricultural Aviation Association.

National Aeronautics and Space Administration. (2019). Unmanned aircraft system (UAS) traffic management (UTM). Retrieved from https://utm.arc.nasa.gov/index.shtml

Skylogic Research. (2018). 2018 Drone market sector report. Retrieved from http://droneanalyst.com/research/research-studies/2018-drone-marketsector-report-purchase 
UAS Identification and Tracking Aviation Rulemaking Committee [UAS ID ARC]. (2017). ARC recommendations final Report. Federal Aviation Administration. Retrieved from https://www.faa.gov/regulations_policies/ rulemaking/committees/documents/media/UAS\%20ID\%20ARC\%20Final \%20Report\%20with\%20Appendices.pdf

Vance, S. M., Wallace, R. J., Loffi, J. M., Jacob, J. D., Dunlap, J. C., \& Mitchell, T. A. (2017). Detecting and assessing collision potential of aircraft and small unmanned aircraft systems (sUAS) by visual observers.

International Journal of Aviation, Aeronautics, and Aerospace, 4(4). https://doi.org/10.15394/ijaaa.2017.1188

Wallace, R. J., Loffi, J. M., Vance, S. M., Jacob, J., Dunlap, J. C., \& Mitchell, T.A. (2018). Pilot visual detection of small unmanned aircraft systems (sUAS) equipped with strobe lighting. Journal of Aviation Technology and Engineering, 7(2). doi:10.7771/2159-6670.1177 